\title{
Arch replacement with collared elephant trunks: The Siena approach
}

\author{
Eugenio Neri, MD, ${ }^{\mathrm{a}}$ Luigi Muzzi, MD, ${ }^{\mathrm{a}}$ Enrico Tucci, MD, ${ }^{\mathrm{a}}$ Marco Cini, MD, ${ }^{\mathrm{b}}$ Lucio Barabesi, DrPh, ${ }^{\mathrm{c}}$
}

Giulio Tommasino, MD, ${ }^{\mathrm{a}}$ and Carmelo Ricci, $\mathrm{MD}^{\mathrm{b}}$

\section{ABSTRACT}

Objective: To illustrate our experience and results in patients with diffuse aneurysmal disease treated with arch replacement using the Siena collared graft, a device designed in 2002 to improve the elephant trunk technique. Results of the first step surgical implant and the subsequent treatment strategies, with extensive use of endovascular techniques, are reported.

Methods: All aortic arch-replacement procedures using the Siena graft between February 2002 and January 2020 were retrospectively analyzed for early and late clinical outcomes.

Results: Of 146 patients ( 54 women, $36.9 \%$ ) with a median age of 69.1 years (interquartile range 58.4-75.0 years), $55(37.6 \%)$ had acute/chronic dissection with false lumen aneurysmal dilatation, $91(62.3 \%)$ had degenerative aneurysms, $45(30.8 \%)$ were redo operations, and $14(9.5 \%)$ had connective tissue disease. First-stage outcomes: $10.9 \%$ 30-day mortality $(n=16) ; 5.4 \%$ stroke $(n=8,6$ disabling, 2 nondisabling; 3 fatal); and $0.6 \%$ paraplegia. Outcomes for 113 second-stage procedures $(77.3 \%, \mathrm{n}=97$ endovascular $[66.4 \%], \mathrm{n}=16$ surgical $[10.9 \%])$ were $5.3 \%$ and $8.8 \%$ 30-day and 180 -day mortality; no stroke; $10.6 \%$ paraplegia. Median followup was 5.7 years (range: $0-18.02$ years) median survival was 16.65 years ( $95 \%$ lower confidence limit, 10.06 years) with no significant difference between aneurysm and dissection patients. Freedom from further treatment was $87.0 \%$ (95\% confidence interval, $79.9 \%-94.7 \%$ ) at 5 years and $71.4 \%$ (95\% confidence interval, $71.4 \%$ $84.7 \%$ ) at 10 years; median time to reintervention was 2.59 years (interquartile range, $0.52-5.20$ years) with no difference $(P=.22)$ between dissection and aneurysm groups.

Conclusions: Siena collared graft represents a reliable platform for the treatment of diffuse aneurysmal disease. This device offers the flexibility required in the treatment of extended aortic lesions and guarantees the choice of the most appropriate approach for treatment completion. In this context, the availability of hybrid grafts has not modified the role of this device in arch surgery. (JTCVS Techniques 2021;6:13-27)

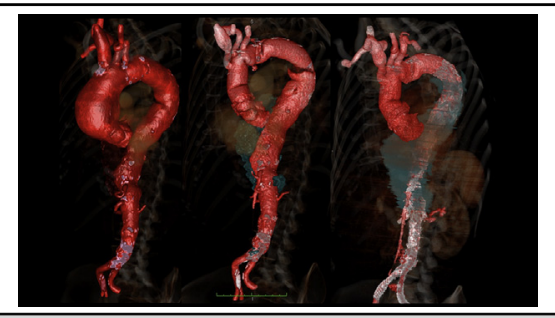

Three steps of a "delayed frozen" elephant trunk approach.

CENTRAL MESSAGE

Arch replacement using Siena collared graft elephant trunk is effective for the treatment of diffuse aortic aneurysmal disease, especially when combined with advanced endovascular techniques.

\section{PERSPECTIVE}

In the early 2000s, the Gelweave Siena graft for elephant trunk arch replacement was designed to facilitate second-stage endovascular completion. Long-term follow-up of a large cohort of patients treated with this technique demonstrate that open surgical techniques and surgical grafts continue to be essential for the treatment of diffuse aneurysmal disease.

See Commentaries on pages 28 and 30.
From the ${ }^{\mathrm{a} A o r t i c}$ Surgery and ${ }^{\mathrm{b}}$ Interventional Radiology Units, Siena University Hospital, Siena; and ${ }^{\mathrm{c}}$ Department of Statistics, Università degli Studi di Siena, Siena, Italy.

Received for publication Nov 10, 2020; accepted for publication Nov 18, 2020; available ahead of print Nov 26, 2020.

Address for reprints: Eugenio Neri, MD, Azienda Ospedaliera Universitaria Senese, Policlinico “Santa Maria alle Scotte," Viale M. Bracci, 53100 Siena, Italy (E-mail: eugenio.neri@unisi.it).

2666-2507

Copyright (C) 2020 The Authors. Published by Elsevier Inc. on behalf of The American Association for Thoracic Surgery. This is an open access article under the CC BY-NCND license (http://creativecommons.org/licenses/by-nc-nd/4.0/).

https://doi.org/10.1016/j.xjtc.2020.11.017 $\checkmark$ Video clip is available online.

In 2002, we introduced a new elephant trunk (ET) surgical graft (the Siena graft) ${ }^{1}$ to treat aortic arch aneurysms and dissection that facilitated hybrid completion or an open surgical second stage (Video 1). This design anticipated dedicated hybrid grafts and the "frozen" ET technique that has since gained popularity; we extensively employed endovascular devices for second-stage completion from the beginning. We describe our approach and report long-term results. 


\section{Abbreviations and Acronyms \\ $\mathrm{CI}=$ confidence interval \\ $\mathrm{CSF}=$ cerebrospinal spinal fluid \\ $\mathrm{CT}=$ computed tomography \\ ET = elephant trunk \\ IQR = interquartile range \\ LCL = lower confidence limit \\ $\mathrm{OR}=$ odds ratio \\ OSR = open surgical repair \\ PAU = penetrating aortic ulcer \\ SINE = stent graft-induced new entry tear \\ TEVAR $=$ thoracic endovascular aortic repair}

\section{METHODS}

This was a retrospective analysis of the clinical records of all patients treated at Azienda Ospedaliera Universitaria Senese, Siena, Italy, between February 2002 and January 2020 (Figure 1) who received a Gelweave (Terumo Aortic; Inchinnan, Glasgow, United Kingdom) Siena collared graft for arch replacement as a part of a staged treatment of diffuse aneurysmal disease (chronic aortic dissection, Marfan syndrome, mega-aorta syndrome, and multiple aneurysm). ${ }^{2}$ Perioperative data were collected from the aortic surgery database; data regarding endovascular materials and imaging follow-up were obtained from the interventional radiology database. Outcomes, including the need for intervention and mortality, were tracked over time. Follow-up information was obtained from hospital outpatients clinic records and by direct contact with the patient, family, cardiologist, and family physician. The Hospital Ethics Committee approved the study; before elective surgery, all patients gave their written and informed consent to the procedures; in emergency cases with impaired consciousness, informed consent was obtained from relatives, unless this delayed the start of treatment ( 2 cases). The Gelweave Siena collared graft (Terumo Aortic) has been described in the literature for use in the ET procedure. $^{3-7}$ Indication for index surgery is based on international guidelines, as well as on the clinical evaluation and computed tomography (CT) angiography of the aorta. Recently, the tool of multidisciplinary case discussion (aortic team), to tailor the treatment on a patient's anatomy and function, has been adopted as a standard. Follow-up CT scans were performed to determine the anatomical outcome of the primary arch replacement and to decide subsequent treatment strategies, such as the choice and sizing of endovascular devices. ${ }^{8-10}$ The criteria to determine second-stage treatment were identical for both surgical and endovascular approaches. Primary treatment was advised if (1) the maximum diameter of the thoracic aorta exceeded $60 \mathrm{~mm}$, (2) if there was a rapid expansion of $>1 \mathrm{~cm} /$ year, or (3) a morphology known to be at high risk of rupture (eg, eccentric dilation/ penetrating aortic ulcer [PAU]). Patients with suspected or documented genetic aortic disorders with a descending thoracic aortic diameter exceeding $55 \mathrm{~mm}$ were considered for repair. All patients requiring endovascular treatment were discussed by a multidisciplinary aortic team that included interventional radiologists and cardiac surgeons.

\section{Operative Technique: The First Stage}

All elective patients underwent extensive cardiopulmonary workup, including coronary angiography and neurovascular imaging. The current Siena graft surgical technique (Video 1) does not differ much from that described in the original report. ${ }^{1}$ Right axillary perfusion was routinely employed for arterial inflow; extrathoracic carotid artery cannulation was used in redo surgery at risk for re-entry catastrophe. ${ }^{11}$ Bilateral hemisphere perfusion was obtained with a cannula inserted into the left

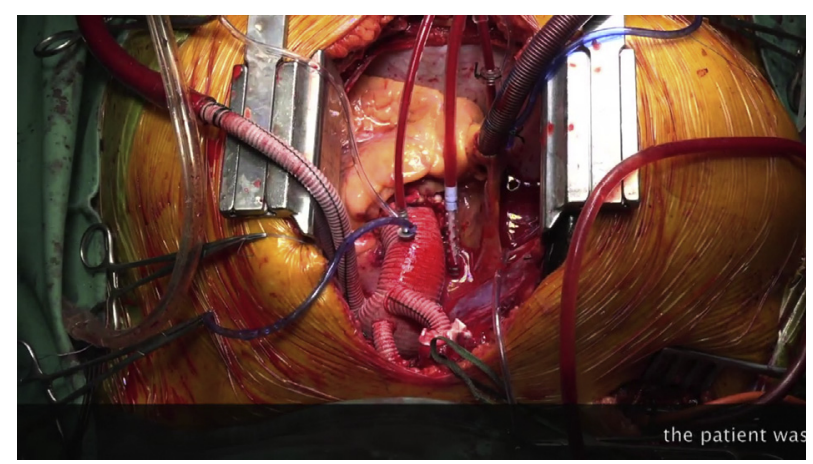

VIDEO 1. The elephant trunk is a revolutionary technique invented by professor Hans Borst in 1983 for the treatment of diffuse aneurysmal disease. In the early years, 2000 , in Siena, we began to think about a prosthesis expressly designed for the ET technique. The idea arose from the possibilities offered by new endovascular stent graft technologies emerging in those years. We sought to take full advantage from them to complete the elephant trunk operations with a less-invasive approach. The term frozen elephant trunk was still to be coined at that time, but that was the direction taken. In addition, with the new design, we wanted to solve some technical problems such as the graft/aorta mismatch at the anastomosis level and we wanted to use multi-branched grafts that made simpler the reconstruction. The new graft was named Dumbo, for the analogy between the Walt Disney's big-eared baby elephant and the ET graft sewing collar. The following part of the video illustrates an aneurysm case treated with our current technique and completed with a branched graft. Video available at: https://www.jtcvs.org/article/S2666-2507(20)30702-1/fulltext.

common carotid artery as described by Kazui and colleagues ${ }^{12}$ and cerebral flow rate was maintained between 10 and $15 \mathrm{~mL} / \mathrm{kg} / \mathrm{min}$ under moderate hypothermic circulatory arrest $\left(26^{\circ} \mathrm{C}\right.$ nasopharyngeal). Nearinfrared spectroscopy was used to monitor oxygen saturation in the frontal lobes. The graft is sutured using either 3-0 polypropylene running suture or 3 interrupted 2.0 ETHIBOND sutures (Ethicon, Somerville, $\mathrm{NJ}$ ) with an additional 3-0 polypropylene running suture line added for hemostasis. A polytetrafluoroethylene-felt ring, which doubles the collar distally, improves hemostasis and reinforces anastomosis. Once the distal anastomosis is completed and the perfusion branch of the graft is connected to a second arterial line for distal perfusion, the anastomosis on the proximal aorta is performed to reduce myocardial ischemic time; perfusion of the graft main body provides better geometry for supraaortic trunk vessel reimplantation and avoids kinking of the branches. When using the ET technique for dissection, preoperative contrast CT assessment of the intimal flap anatomy should rule out potential problems of distal malperfusion; distal fenestration can be performed in such circumstances. If the flow can be safely redirected into the true lumen at the level of the distal anastomosis without risking malperfusion, long ET grafts-size is calculated on the perimeter of the true lumen-are preferred and are introduced and advanced into the true lumen using an Amplatz Goose Neck snare device (Medtronic, Minneapolis, Minn) by the radiologist under guidance of a C-arm image intensifier (OEC 9600 Vascular; GE Healthcare, Munich, Germany) or using transesophageal echocardiography during patient preparation. The distal end of the ET graft is captured by the snare catheter and gently pulled into the correct lumen, thus avoiding folding or kinking. The goal is to induce proximal false lumen exclusion by redirecting blood flow into the true lumen, avoiding an immediate second-stage procedure. The correct size of graft is calculated using the perimeter of the true lumen at different levels (perimeter $/ \pi$ ). 
Arch replacement with collared ET: the Siena approach

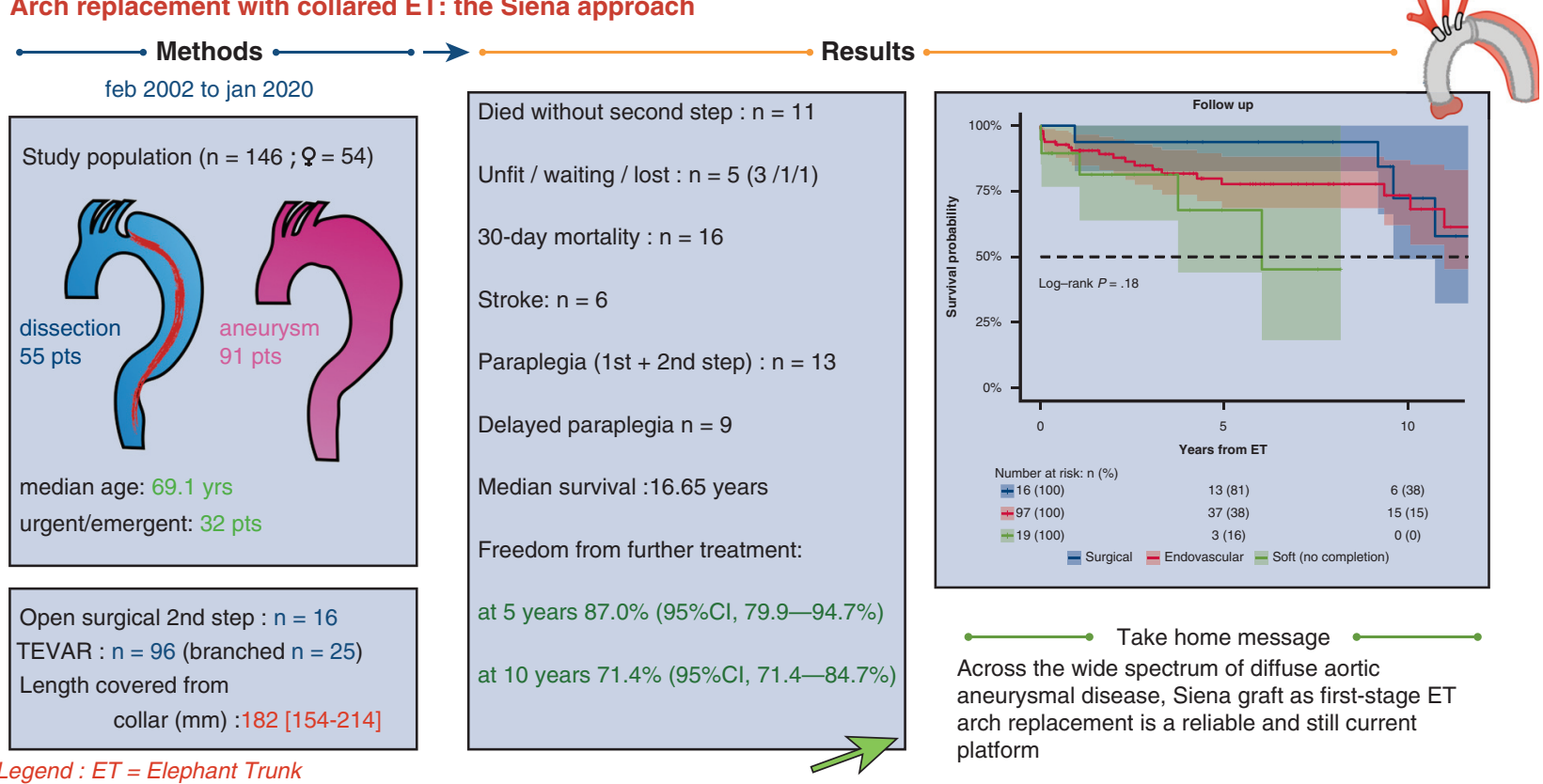

FIGURE 1. Study outline and the main results of our experience. ET, Elephant trunk; TEVAR, thoracic endovascular repair.

\section{Operative Technique: Second-Stage Completion (Surgical)}

The surgical second stage is similar to a standard descending thoracic or thoracoabdominal aortic aneurysm repair and performed after adequate patient recovery. ${ }^{11}$ A thoracic (or thoracoabdominal) incision is made, and the descending aorta exposed. ${ }^{13}$ The distal end of the graft from the first stage is identified. Partial or full cardiopulmonary bypass with or without circulatory arrest is employed and the distal end of the graft clamped. The descending aortic aneurysm is opened, the ET identified, and the new prosthetic graft is anastomosed proximally, intercostal and visceral arteries are reimplanted onto the graft body (Gelweave Coselli; Terumo Aortic) as needed and the distal end of the graft is anastomosed to the aorta beyond the aneurysm.

\section{Operative Technique: Second-Stage Completion (Endovascular)}

The endovascular option can be part of a 2-stage operation or can be performed during the index procedure after cardiopulmonary bypass. In the latter, the thoracic aortic stent-graft can be inserted with the aid of intraoperative fluoroscopy into the descending aorta, using the perfusion side branch of the Gelweave Siena collared graft. The planning of all endovascular procedures was performed by the same operator using recent (3 months) CT angiography. Full technical details have been described in a previous report. ${ }^{14}$ The technique differs with regard to the underlying pathology, dissection, or aneurysm. In dissected patients stent grafts were positioned into the true lumen only in those cases that showed favorable anatomical conditions (ie, visceral arteries arising from the true lumen) or to relieve dynamic compression of the true lumen. In some cases covering a distal re-entry tear in the thoracic aorta - and thus obtaining a partial thrombosis of the false lumen-was an acceptable provisional solution. ${ }^{15}$ When this approach was not safe or possible, patients underwent an extended longitudinal fenestration enabling full expansion of a stent-graft to cover large, descending thoracic aortic aneurysms. This technique has the advantage of converting the double lumen-dissected aorta into a single lumen, allowing branched stent-grafts (designed for aneurysm treatment) to be used. ${ }^{16}$ Endovascular fenestration was done using a "body floss" type wire technique where both ends of a snared wire were pulled longitudinally (caudally) across a chronic dissection membrane; organized dissection membranes seen in the setting of chronic dissection were penetrated using a radiofrequency device. ${ }^{17}$

Endovascular repair of aneurysms changed according to anatomical extension. In the case of lesions involving the descending aorta above the celiac trunk, straight or tapered endografts were employed, whereas in thoracoabdominal lesions, branched devices were used. In all cases, proximal stent-graft landing was within the new, surgical ET neck and with at least 2-cm overlap. In challenging vessel anatomy, like tortuosity or steep angles, a brachiofemoral loop technique facilitated endoprosthesis positioning.

Some patients could not wait for a custom-made endovascular approach: in urgent settings, off-the-shelf branched devices or a parallel graft (chimney) technique were used to ensure visceral perfusion. In elective cases, custom-made devices were used to preserve the native anatomy; branch completion was performed with self-expandable covered stents (VIABAHN, W. L. Gore \& Associates, Inc, Flagstaff, Ariz).

\section{Operative Technique: Spinal Cord-Protection Strategies}

Spinal cord protection included systemic moderate hypothermia, early reperfusion of the thoracoabdominal aorta (as soon as the distal anastomosis was completed), and mandatory left subclavian artery revascularization (left subclavian artery selective perfusion was never used); somatosensory potentials monitoring was not available as routine. ${ }^{18-21}$

Cerebrospinal spinal fluid (CSF) drainage was employed when: (1) extensive thrombosis of the false lumen after exclusion of dissection intimal entries was expected; (2) an adjunctive (intraoperative) thoracic endovascular aortic repair (TEVAR) procedure would cover at least twothirds of the thoracic aorta; (3) patients had previous abdominal aortic repair. Second-stage surgical treatment involved routine CSF drainage, 
mild hypothermia, distal perfusion, sequential clamping, and maximum reimplantation of intercostal arteries. For second-stage TEVAR and with straight grafts, local anesthesia with conscious patients and no CSF drainage was standard. In more complex repair (branched grafts or straight grafts extending to the celiac axis), CSF drainage was routine. Immediately after stent-graft deployment, mean blood pressure was raised $>80 \mathrm{~mm} \mathrm{Hg}$ and CSF drained until postoperative day 3 to keep CSF pressure below $10 \mathrm{~mm} \mathrm{Hg}$. CSF drainage was resumed if late paraplegia occurred. For the first 48 to 72 hours after TEVAR, the mean arterial pressure goal was 90 to $100 \mathrm{~mm} \mathrm{Hg}$ (systolic blood pressure, $120-150 \mathrm{~mm} \mathrm{Hg}$ ), using volume and vasoactive drugs. ${ }^{22}$

\section{STATISTICAL ANALYSIS}

Distribution-free statistical methods were used to avoid unrealistic functional assumptions; statistical routines, implemented in the StatXact, LogXact (Cytel Software Corporation, Cambridge, Mass), R 3.6.1 (The Comprehensive $\mathrm{R}$ Archive Network; http://www.R-project.org) and SPSS 24.0 (IBM Corp, Armonk, NY) statistical packages were employed. Categorical variables were expressed as percentages; continuous variables were expressed as the median and interquartile range (IQR) (unless otherwise specified). A 2-tailed permutation test was performed to test differences among continuous variables. The Fischer exact test was used to test categorical variables. Mortality data were analyzed using univariate and multivariate logistic regression with the response variable being 30-day mortality. Multivariate models were applied to isolate the effect of each factor adjusted for all other factors: a .05 level $(P<.05)$ was used as a screening criterion for selection of candidate variables. To avoid problems created by multicollinearity, variables that were too highly correlated among themselves were included at different times in different models. A backwards procedure was used. A Wald $\chi^{2}$ test was used for testing the significance of individual coefficients. The results are reported as odds ratios (OR) with $95 \%$ confidence intervals (CIs). Survival data were analyzed with standard Kaplan-Meier actuarial techniques for estimation of survival probabilities and freedom from distal aortic progression requiring further treatment and compared with log-rank tests. Median duration of followup was calculated using the reversed Kaplan-Meier estimator method. Cox proportional hazards regression, with a backwards procedure, was used to determine independent predictors of late death and distal aortic evolution requiring further treatment. The probability for entry and removal into the model was set to .05 and .10, respectively. Independent predictor variables that contributed to the final multivariate model were considered significant risk factors if the $P$ value for improvement in $\chi^{2}$ was .05 or less. ORs and $95 \%$ CIs were reported to indicate the effect size.

\section{RESULTS}

A total of 146 patients underwent aortic arch replacement for extensive thoracic or thoracoabdominal aortic diseases;
$54(36.9 \%)$ women and $92(63.0 \%)$ men with a median age of 69.1 years (IQR, 59.5-75.0); $55(37.6 \%)$ had acute or chronic dissection with aneurysmal dilatation of the false lumen, $91(62.3 \%)$ had degenerative aneurysms, 45 $(30.8 \%)$ involved redo operations ( 25 first redo, 14 second redo, 6 third), and 14 (9.5\%) had connective tissue disease (Marfan syndrome, 8 with chronic dissection) (Table 1). The procedure was planned in 114 patients $(78.0 \%)$ and urgent/emergent in $32(21.9 \%)$. Eight emergent cases included in the aneurysm group involved ruptured PAUs treated with the Gelweave Siena graft and intraoperative TEVAR before 2012 (before hybrid grafts became available); another 12 elective PAU cases were treated similarly. In 43 cases, the goal of the ET arch replacement was to provide an adequate surgical or endovascular neck for the treatment of downstream aortic aneurysm or dissection (even in the absence of relevant aneurysmal arch size) (Table 2). Mean aneurysm diameter (maximal dilatation) was $58.7 \pm 8.4 \mathrm{~mm}$ (range, 50-78). Concomitant operative procedures included root repair/replacement $(n=30,20.5 \%)$, aortic valve surgery $(\mathrm{n}=14,9.5 \%)$, and TEVAR $(\mathrm{n}=12$, $8.2 \%$ ) (Table 3). Early (30-day and in-hospital) mortality rate after the index procedure was $10.9 \%(\mathrm{n}=16)$ without a significant difference between aneurysm $(\mathrm{n}=11)$ and dissection patients $(\mathrm{n}=5)(P=.18)$. Causes of death included postoperative low cardiac output with multiorgan failure $(\mathrm{n}=4)$; visceral ischemia $(\mathrm{n}=2)$; stroke $(\mathrm{n}=3)$; lung infection/sepsis $(\mathrm{n}=4)$; and cardiac arrest/refractory arrhythmia $(\mathrm{n}=3)$ (Table 4$)$. Another 2 patients died within 180 days of the index procedure (respiratory failure with complications of tracheostomy and ventricular fibrillation during dialysis). Major stroke occurred in 6 patients (4.1\%; fatal in 3), minor stroke in $2(1.3 \%)$; temporary cognitive dysfunction was $13 \%$ (19 patients). Paraparesis occurred in 1 case after ET $(0.6 \%)$. Results of univariate analysis are reported in Table 5. A multivariate logistic regression analysis model indicated that early mortality was related with age at operation $>70$ years $(P=.02$; OR, 3.94; 95\% CI, 1.74-3.2); postoperative stroke $(P=.001 ;$ OR, $9.49 ; 95 \%$ CI, 2.93-30.65); combined root and redo operations $(P=.05$; OR, $3.58 ; 95 \% \mathrm{CI}$, 1.94-13.69); low cardiac output $(P=.013$; OR, 3.09; 95\% CI, 2.06-14.65); acute renal failure $(P=.004$; OR, $8.13 ; 95 \%$ CI, 1.93-3.38).

\section{Outcomes of Second-Stage and Further Operations}

Of the 146 patients who underwent the ET procedure, 130 were discharged alive ( $10.9 \%$ overall mortality after ET); 11 patients $(7.5 \%)$ died before the second stage (6 within 30 days of the index procedure); and 8 patients $(5.4 \%)$ received endovascular completion before in-hospital death (Table 3$)$. Three $(2.3 \%)$ of the 130 patients discharged alive after the index procedure died before second-stage completion, 16 of $130(12.3 \%)$ were treated with open (descending 
TABLE 1. Patient demographics and baseline characteristics

\begin{tabular}{|c|c|c|c|c|}
\hline & $\begin{array}{c}\text { All } \\
\mathrm{N}=146\end{array}$ & $\begin{array}{c}\text { Dissection } \\
\mathbf{n}=\mathbf{5 5}\end{array}$ & $\begin{array}{c}\text { Aneurysm } \\
\mathbf{n}=\mathbf{9 1}\end{array}$ & $P$ value \\
\hline Age, y & $69.1[59.5-75.0]$ & $61.3[50.9-71.5]$ & $71.8[65.3-78.0]$ & $<.001$ \\
\hline Male/female & $92 / 54$ & $39 / 16$ & $58 / 38$ & $\mathrm{~ns}$ \\
\hline $\mathrm{EF}(\%)$ & $56[55-60]$ & $56[55-60]$ & $56[55-60]$ & $\mathrm{ns}$ \\
\hline Emergent/urgent & $32(21.9 \%)$ & $21(38.1 \%)$ & $11(12.0 \%)$ & $<.001$ \\
\hline Elective & $114(78.0 \%)$ & $34(61.8 \%)$ & $80(87.9 \%)$ & $<.001$ \\
\hline Redo surgery & $45(30.8 \%)$ & $34(61.8 \%)$ & $11(12.0 \%)$ & $<.001$ \\
\hline Not first redo surgery & $20(13.6 \%)$ & $17(30.9 \%)$ & $3(3.2 \%)$ & $<.001$ \\
\hline Marfan syndrome & $14(9.5 \%)$ & $8(14.5 \%)$ & $6(6.5 \%)$ & ns \\
\hline Difficult aortic anatomy* & $9(6.1 \%)$ & $3(5.4 \%)$ & $6(6.5 \%)$ & ns \\
\hline Smoking & $66(45.2 \%)$ & $13(23.6 \%)$ & $53(58.2 \%)$ & $<.0001$ \\
\hline Diabetes & $9(6.1 \%)$ & $1(1.8 \%)$ & $8(8.7 \%)$ & ns \\
\hline Coronary disease & $16(10.9 \%)$ & $2(3.6 \%)$ & $14(15.3 \%)$ & .018 \\
\hline Hypertension & $104(71.2 \%)$ & $38(69.0 \%)$ & $66(72.5 \%)$ & $\mathrm{ns}$ \\
\hline Dyslipidemia & $52(35.6 \%)$ & $17(30.9 \%)$ & $35(38.4 \%)$ & ns \\
\hline Peripheral arterial disease & $34(23.2 \%)$ & $8(14.5 \%)$ & $26(28.5 \%)$ & .02 \\
\hline Previous vascular surgery & $18(12.3 \%)$ & $4(7.2 \%)$ & $14(15.3 \%)$ & ns \\
\hline Dialysis & $3(2.0 \%)$ & $0(0 \%)$ & $3(3.2 \%)$ & $\mathrm{ns}$ \\
\hline Preoperative stroke & $10(6.8 \%)$ & $6(10.9 \%)$ & $4(4.3 \%)$ & ns \\
\hline COPD & $38(26.0 \%)$ & $5(9.0 \%)$ & $33(6.2 \%)$ & $<.0001$ \\
\hline Pulmonary hypertension & $8(5.4 \%)$ & $1(1.8 \%)$ & $7(7.6 \%)$ & $\mathrm{ns}$ \\
\hline EuroSCORE I & $10[7-11]$ & $10[7-11]$ & $10[7.5-11.5]$ & $\mathrm{ns}$ \\
\hline
\end{tabular}

Values are $\mathrm{n}(\%)$ or median [interquartile range]. $n s$, Not significant; $E F$, ejection fraction; $C O P D$, chronic obstructive pulmonary disease. *Kommerell diverticulum, right aortic arch.

aorta) surgical repair (OSR), 19 of $130(14.6 \%)$ did not require a second stage due to satisfactory thrombosis of the false lumen, 3 were considered unfit for further treatment, 1 is waiting for an operation, and 1 was lost to follow-up before completion. In addition to 12 TEVARs performed as part of the index procedure, 34 were performed within a week, meaning that $66.4 \%$ of patients (97/146) had second-stage TEVAR (Table 6). The median interval from index procedure to second stage (OSR or TEVAR) was 65 days (IQR, 19-182). Eighteen patients $(\mathrm{n}=15$, $15.4 \%$, TEVAR and $\mathrm{n}=3,18.7 \%$, OSR) subsequently required a graft extension (third-stage TEVAR).
There were 6 early deaths after the second stage ( 3 OSR, 3 TEVAR; $P=.03$ ); causes of death were cardiac failure/ low cardiac output $(n=2)$ and pneumonia, intractable lung bleeding, left renal rupture with retroperitoneal hematoma, and subsequent multiorgan failure and sepsis $(\mathrm{n}=1$ in each case). Another 4 patients died within 180 days of the second stage (1 OSR, 3 TEVAR; $P=.33$ ).

No stroke was observed after the second-stage procedures. Paraplegia/paraparesis occurred in 12 patients $(2$ OSR, 10 TEVAR; $P=.30$ ); 8 patients with paraplegia had a branched graft implanted; this rate of paraplegia was significantly greater compared with those who received

TABLE 2. Indications for treatment of 146 patients who underwent the elephant trunk procedure

\begin{tabular}{llll}
\hline \multicolumn{1}{c}{ Class type $(\mathbf{n})$} & \multicolumn{1}{c}{ Indication } & $\mathbf{n}(\%)$ & Notes \\
\hline Dissection $(\mathrm{n}=55)$ & Type A acute & $7(12.7)$ & 2 post-traumatic \\
& Type A residual & $34(61.8)$ & \\
& Type B & $14(25.4)$ & Neck creation \\
Aneurysm $(\mathrm{n}=91)$ & Distal arch + thoracic aneurysm & $20(21.9)$ & Neck creation \\
& Distal arch + thoracoabdominal aneurysm & $9(9.8)$ & Neck creation \\
& Arch aneurysm + thoracic aneurysm & $17(18.6)$ & 1 aortitis \\
& Arch aneurysm + thoracoabdominal aneurysm & $25(27.4)$ & All before April 2012 \\
& Arch penetrating aortic ulcer & $20(21.9)$ & \\
\hline
\end{tabular}


TABLE 3. Operative and second-stage details of 146 patients who underwent the elephant trunk procedure

\begin{tabular}{|c|c|c|c|c|}
\hline Index procedure & $\begin{array}{c}\text { All } \\
N=146\end{array}$ & $\begin{array}{c}\text { Dissection } \\
\mathbf{n}=55\end{array}$ & $\begin{array}{c}\text { Aneurysm } \\
\mathbf{n}=\mathbf{9 1}\end{array}$ & $P$ value \\
\hline TEVAR (intraoperatively) & $12(8.2 \%)$ & $2(3.6 \%)$ & $10(.9 \%)$ & ns \\
\hline CABG & $9(6.1 \%)$ & $1(1.8 \%)$ & $8(8.7 \%)$ & ns \\
\hline Aortic valve surgery & $14(9.5 \%)$ & $4(7.2 \%)$ & $10(10.9 \%)$ & ns \\
\hline Root replacement or repair & $30(20.5 \%)$ & $13(23.6 \%)$ & $17(18.6 \%)$ & ns \\
\hline Vertebral artery from arch & $12(8.2 \%)$ & $2(3.6 \%)$ & $10(10.9 \%)$ & ns \\
\hline $\mathrm{CPB}$ time, $\min$ & 173 [145-209] & $179[144-218]$ & $173[147-201]$ & ns \\
\hline HCA time, min & 39 [33-51] & 45 [38-54] & $36[32-50]$ & ns \\
\hline Crossclamp time, min & $100[75-121]$ & 97 [77-119] & 100 [75-119] & ns \\
\hline \multicolumn{5}{|l|}{ SAT patency (postoperative) } \\
\hline Carotid branch closure & $1(0.6 \%)$ & $1(1.8 \%)$ & $0(0 \%)$ & ns \\
\hline Subclavian branch closure & $2(1.3 \%)$ & $1(1.8 \%)$ & $1(1.0 \%)$ & ns \\
\hline Blood loss, mL & $300[150-450]$ & 275 [150-400] & $310[200-500]$ & ns \\
\hline Transfusion, units & 5 [2-9] & $4.5[2-6]$ & $5[3-10]$ & ns \\
\hline Mechanical ventilation, $\mathrm{h}$ & 48.0 [19.6-113.9] & $34.8[17.0-125.0]$ & $56.1[23.0-109.6]$ & ns \\
\hline Intensive care, $d$ & 5 [3.5-8.3] & $4.8[3.5-8.6]$ & $5.0[3.7-7.3]$ & ns \\
\hline \multicolumn{5}{|l|}{ Second stage } \\
\hline Died before second stage & $11(7.5 \%)$ & $4(7.2 \%)$ & $7(7.6 \%)$ & ns \\
\hline No second stage & $29(19.8 \%)$ & $17(30.9 \%)$ & $12(13.1 \%)$ & .006 \\
\hline Not necessary & $19(13.0 \%)$ & $16(20.9 \%)$ & $3(3.2 \%)$ & $<.0001$ \\
\hline Pending & $1(0.6 \%)$ & $0(0 \%)$ & $1(1.0 \%)$ & ns \\
\hline Unfit & $3(2.0 \%)$ & $0(0 \%)$ & $3(3.2 \%)$ & ns \\
\hline Lost to follow-up & $1(0.6 \%)$ & $0(0 \%)$ & $1(1.0 \%)$ & ns \\
\hline Surgical second stage & $16(10.9 \%)$ & $6(10.9 \%)$ & $10(10.9 \%)$ & ns \\
\hline Thoracoabdominal & $10(6.8 \%)$ & $5(9.0 \%)$ & $5(5.4 \%)$ & ns \\
\hline Thoracic & $6(4.1 \%)$ & $1(1.8 \%)$ & $5(5.4 \%)$ & ns \\
\hline Endovascular second stage & $97(66.4 \%)$ & $29(52.7 \%)$ & $68(74.7 \%)$ & .003 \\
\hline Third stage/stent-graft extension & $18(12.3 \%)$ & $5(9.0 \%)$ & $13(14.2 \%)$ & ns \\
\hline
\end{tabular}

Values are n (\%) or median [interquartile range]. TEVAR, Thoracic endovascular aortic repair; $n s$, not significant; $C A B G$, coronary artery bypass grafting; $C P B$, cardiopulmonary bypass; $H C A$, hypothermic circulatory arrest; $S A T$, supra-aortic trunk.

1 or more straight stent-grafts $(P<.0001)$; in comparison with patients who received surgical thoracoabdominal replacement, the paraplegia rate was not significantly different $(2 / 10$ vs $8 / 23 ; P=.2)$. Delayed paraplegia was the prominent presentation, which occurred in 9 patients (median postoperative day 2 , range 1-8).

The stent-grafts used to "freeze" the Siena grafts (alone or in combination with other devices) were Terumo Aortic Relay in 44 patients, Cook Zenith $(\mathrm{n}=24)$, Jotec custommade $(\mathrm{n}=22)$; Gore C-TAG $(\mathrm{n}=16)$, Cook T-BRANCH $(\mathrm{n}=7)$, Cook custom-made $(\mathrm{n}=5)$, Endomed Endofit $(\mathrm{n}=4)$, and Medtronic Talent $(\mathrm{n}=1)$. Within the TEVAR group, branched grafts were used in 35 patients $(n=25$ at second stage, $\mathrm{n}=10$ at third stage); straight grafts were used in 79 patients $(\mathrm{n}=72$ at second stage, $\mathrm{n}=7$ at third stage, with an average number of 1.77 stent-grafts per patients and a median length covered (measured on the aortic centerline) of $182 \mathrm{~mm}$ (IQR, 155-338 mm). Further reinterventions were indicated for aneurysm progression $(\mathrm{n}=12)$ or type Ib endoleaks $(\mathrm{n}=5)$.

\section{Follow-up Outcomes}

Follow-up was $99.3 \%$ complete; 1 patient was lost to follow-up 5 years after the index procedure. Median follow-up was 5.7 years (IQR 1.8-9.5 years; range, 0-18.0 $2)$; median survival was 16.6 years $(95 \%$ lower confidence limit [LCL], 10.0 years) without a significant difference between aneurysm and dissection patients $(P=.63)$; 16.6 years (95\% LCL 10.0 years) versus 10.7 years $(95 \%$ LCL 9.3 years). Figure 2 shows the Kaplan-Meier estimates for overall survival after ET: $75.2 \%(95 \% \mathrm{CI}, 67.7 \%$ $83.5 \%)$ at 5 years; $64.2 \%(95 \% \mathrm{CI}, 53.6 \%-76.8 \%)$ at 10 years; and $52.8 \%(95 \% \mathrm{CI}, 39.7 \%-70.3 \%)$ at 15 years. For patients with aneurysm $(\mathrm{n}=91)$, survival estimates at 5 , 10 , and 15 years were: $74.8 \%$ (95\% CI, $65.4 \%-85.5 \%$ ), $68.3 \%(95 \% \mathrm{CI}, 56.6 \%-82.3 \%)$, and $63.0 \%$ (95\% CI, 
TABLE 4. Outcomes of 146 patients who underwent the elephant trunk procedure

\begin{tabular}{|c|c|c|c|c|}
\hline & $\begin{array}{c}\text { All } \\
n=146\end{array}$ & $\frac{\text { Dissection }}{n=55}$ & $\frac{\text { Aneurysm }}{n=91}$ & $P$ value \\
\hline 30-d mortality & $16(10.9 \%)$ & $5(9.0 \%)$ & $11(12.0 \%)$ & ns \\
\hline Mortality 30-180 d & $2(1.3 \%)$ & $1(1.8 \%)$ & $1(1.0 \%)$ & ns \\
\hline \multicolumn{5}{|l|}{ Paraplegia } \\
\hline After index elephant trunk & $1(0.6 \%)$ & $1(1.8 \%)$ & $0(0 \%)$ & ns \\
\hline After second-stage TEVAR & $10(6.8 \%)$ & $3(5.4 \%)$ & $7(7.6 \%)$ & ns \\
\hline After second-stage OSR & $2(1.3 \%)$ & $0(0 \%)$ & $2(2.1 \%)$ & ns \\
\hline Major stroke & $6(4.1 \%)$ & $3(5.4 \%)$ & $3(3.2 \%)$ & ns \\
\hline Minor stroke & $2(1.3 \%)$ & $0(0 \%)$ & $2(2.1 \%)$ & ns \\
\hline Cognitive dysfunction/delirium & $19(13.0 \%)$ & $8(14.5 \%)$ & $11(12.0 \%)$ & ns \\
\hline Renal failure/dialysis & $20(13.6 \%)$ & $6(10.9 \%)$ & $14(15.3 \%)$ & $\mathrm{ns}$ \\
\hline Respiratory insufficiency & $54(36.9 \%)$ & $26(47.2 \%)$ & $28(30.7 \%)$ & .01 \\
\hline Lung infection/positive BAL & $19(13.0 \%)$ & $5(9.0 \%)$ & $14(15.3 \%)$ & ns \\
\hline Sepsis & $5(3.4 \%)$ & $3(5.4 \%)$ & $2(2.1 \%)$ & ns \\
\hline Tracheostomy & $16(10.9 \%)$ & $4(7.2 \%)$ & $12(13.1 \%)$ & ns \\
\hline Perioperative myocardial infarct & $1(0.6 \%)$ & $1(1.8 \%)$ & $0(0 \%)$ & ns \\
\hline Cardiac arrest & $10(6.8 \%)$ & $6(10.9 \%)$ & $4(4.3 \%)$ & ns \\
\hline Cardiac failure/low cardiac output & $26(17.0 \%)$ & $11(20 \%)$ & $15(16.4 \%)$ & ns \\
\hline Atrial fibrillation & $36(24.6 \%)$ & $13(23.6 \%)$ & $23(25.2 \%)$ & ns \\
\hline Visceral ischemia & $3(2.0 \%)$ & $1(1.8 \%)$ & $3(3.2 \%)$ & ns \\
\hline Sternal re-entry & $17(11.6 \%)$ & $7(12.7 \%)$ & $10(10.9 \%)$ & ns \\
\hline Delayed closure* & $17(11.6 \%)$ & $9(16.3 \%)$ & $8(8.7 \%)$ & ns \\
\hline
\end{tabular}

Values are n (\%). ns, Not significant; TEVAR, thoracic endovascular repair; $O S R$, open surgical repair; $B A L$, bronchoalveolar lavage. $*$ Mediastinal packing for bleeding or temporary ventricular dysfunction.

49.4\%-80.4\%); for dissection patients $(\mathrm{n}=55)$, survival estimates were $75.4 \%(95 \% \mathrm{CI}, 63.4 \%-89.7 \%)$ at 5 years and $56.6 \%$ (95\% CI, 38.6\%-83.3\%) at 10 years (Figure 3 ). The log-rank test did not show significant differences between the survival rates of the 2 groups over time $(P=.45)$. Figure 4 shows no statistically significant differences in survival after ET according to treatment (OSR vs TEVAR vs classical, unstented or "soft" ET) $(P=.18)$ : median survival after surgical second step was over 15 years (25th percentile, 9.61 years) versus TEVAR, 16.65 years (25th percentile, 9.36 years) and unstented (soft) 6.02 years (25th percentile, 3.74 years). Kaplan-Meier estimates for OSR were 5 and 10 years $93.8 \%$ (95\% CI, 82.6\%$100 \%)$ and $59.7 \%(95 \% \mathrm{CI}, 32.2 \%-100 \%)$ at 15 years; for TEVAR $77.7 \%$ (95\% CI, $68.5 \%-88.0 \%$ ), $73.4 \%$ (95\% CI, 62.0\%-89.9\%), 61.3\% (95\% CI, 45.3\%$83.1 \%$ ), respectively at 5,10 , and 15 years. For unstented (soft) ET at 5 years, it was $67.8 \%$ (95\% CI, 44\%-100\%). There were 24 late deaths: 11 in the dissection group and 13 in the aneurysm group. The causes of death were aortic-related in 11 patients ( 5 in the dissection group) and unrelated to aortic condition in 10 patients (unknown in 3 cases). In detail, vascular-related fatal complications included 3 iliac ruptures (2 dissection patients); late stent graft-induced intimal new entry (SINE) with malperfusion (1 dissection patient); 1 ruptured coronary artery button pseudo-aneurysm; one innominate artery rupture (dissection); 3 thoracic aneurysm rupture for persisting endotension/endoleak; 1 surgical graft infection (aneurysm); 1 aortoesophageal fistula (aneurysm), and 1 thrombosis of iliac branch resulting in limb necrosis (aneurysm). Figure 5 illustrates the Kaplan-Meier curves of freedom from reintervention after ET completion (OSR vs TEVAR; $P=.86)$. Figure 6 illustrates the Kaplan-Meier curves of freedom for reintervention after ET completion (dissection vs aneurysm patients; $P=.39$ ). Further treatments were indicated for aneurysm progression $(\mathrm{n}=13)$ and type $\mathrm{Ib}$ endoleaks $(n=4)$. The Kaplan-Meier analysis included only major interventions. Freedom from further treatment was $87.0 \%(\mathrm{n}=11)(95 \% \mathrm{CI}, 79.9 \%-94.7 \%)$ at 5 years and $71.4 \%(95 \% \mathrm{CI}, 71.4 \%-84.7 \%)$ at 10 years. In patients who had reintervention, the median time to reintervention was 2.59 years (IQR, 0.52-5.20 years) with no difference $(P=.22)$ between dissection and aneurysm groups. Among the 17 patients who required further major treatment, 10 received branched stent-grafts and 7 , standard stent-grafts. 
TABLE 5. A univariate analysis of perioperative risk factors on operative mortality

\begin{tabular}{|c|c|c|c|c|}
\hline \multirow[b]{2}{*}{ Risk factor } & \multicolumn{2}{|c|}{ Operative death (30 d) } & \multicolumn{2}{|c|}{ Univariate analysis } \\
\hline & Yes* $(n=16)$ & No* $(n=130)$ & $P$ & Odds ratio $(95 \% \mathrm{CI})$ \\
\hline Female sex & $6(11.1 \%)$ & $48(88.9 \%)$ & $\mathrm{ns}$ & \\
\hline Male sex & $10(10.9 \%)$ & $82(89.1 \%)$ & ns & \\
\hline Age, y & $73.2(70.8 .-79.6)$ & $67.5(57.3-74.9)$ & .04 & $1.056(0.999-1.117)$ \\
\hline Age $>70 y$ & $12(16.7 \%)$ & $60(83.3 \%)$ & .02 & $3.50(1.07-11.42)$ \\
\hline Aneurysm & $11(12.1 \%)$ & $80(87.9 \%)$ & ns & \\
\hline Dissection & $5(9.1 \%)$ & $50(90.9 \%)$ & $\mathrm{ns}$ & \\
\hline Marfan syndrome & 0 & $14(100 \%)$ & $\mathrm{ns}$ & \\
\hline Body surface area, $\mathrm{m}^{2}$ & $1.84(1.67-2.17)$ & $1.89(1.73-2.01)$ & $\mathrm{ns}$ & \\
\hline Thoracoabdominal extension & $9(11.5 \%)$ & $69(88.5 \%)$ & ns & \\
\hline Redo surgery (all) & $6(13.3 \%)$ & $39(86.7 \%)$ & ns & \\
\hline Root surgery & $5(16.7 \%)$ & $25(83.3 \%)$ & $\mathrm{ns}$ & \\
\hline Redo and root surgery & $4(25.0 \%)$ & $12(75.0 \%)$ & .05 & $3.28(0.91-11.76)$ \\
\hline Intraoperative second-stage & $2(10.0 \%)$ & $18(90 \%)$ & $\mathrm{ns}$ & \\
\hline Hypertension & $7(6.7 \%)$ & $97(93.3 \%)$ & .013 & $0.26(0.09-0.77)$ \\
\hline Nicotine abuse & $10(15.1 \%)$ & $56(84.8 \%)$ & $\mathrm{ns}$ & \\
\hline Dyslipidemia & $3(5.8 \%)$ & $49(94.2 \%)$ & $\mathrm{ns}$ & \\
\hline Diabetes & $1(11.1 \%)$ & $8(88.9 \%)$ & ns & \\
\hline Ejection fraction (\%) (continuous) & $55(52.5-60.0)$ & $60(55-60)$ & ns & \\
\hline Ejection fraction $(<40 \%)$ & $3(30.3 \%)$ & $7(70.0 \%)$ & $\mathrm{ns}$ & \\
\hline Recent MI & 0 & $3(100 \%)$ & $\mathrm{ns}$ & \\
\hline Peripheral arterial disease & $6(17.6 \%)$ & $28(82.3 \%)$ & ns & \\
\hline Urgent/emergent & $9(28.1 \%)$ & $23(71.9 \%)$ & .002 & $6.54(2.21-19.34)$ \\
\hline Plasma creatinine $>2.5 \mathrm{mg} / \mathrm{dL}$ & $2(12.5 \%)$ & $14(87.5 \%)$ & ns & \\
\hline Plasma creatinine, $\mathrm{mg} / \mathrm{dL}$ (continuous) & $1.3(1.1-1.6)$ & $1.0(0.8-1.1)$ & .008 & $1.66(0.82-3.33)$ \\
\hline Preoperative stroke & $2(20.0 \%)$ & $8(80.0 \%)$ & $\mathrm{ns}$ & \\
\hline Preoperative neurologic dysfunction & $1(16.7 \%)$ & $5(83.3 \%)$ & $\mathrm{ns}$ & \\
\hline COPD & $2(5.3 \%)$ & $36(94.7 \%)$ & $\mathrm{ns}$ & \\
\hline EuroSCORE I & $10(6.7-11.7)$ & $10(7.0-11.0)$ & $\mathrm{ns}$ & \\
\hline 1 postoperative complication & $14(14.0 \%)$ & $86(86.0 \%)$ & $\mathrm{ns}$ & \\
\hline$>1$ postoperative complication & $14(19.4 \%)$ & $58(80.6 \%)$ & .001 & $8.69(1.89-39.79)$ \\
\hline Delayed closure & $4(23.5 \%)$ & $13(76.5 \%)$ & $\mathrm{ns}$ & \\
\hline Sternal re-entry & $5(20 \%)$ & $20(80 \%)$ & $\mathrm{ns}$ & \\
\hline Sternal re-entry cardiac causes & $2(40 \%)$ & $3(60 \%)$ & ns & \\
\hline Low cardiac output & $7(26.9 \%)$ & $19(73.1 \%)$ & .01 & $4.54(1.51-13.67)$ \\
\hline Vasoactive drugs $>48 \mathrm{~h}$ & $6(25.0 \%)$ & $18(75.0 \%)$ & .02 & $3.73(1.21-11.53)$ \\
\hline Perioperative MI & 0 & 0 & ns & \\
\hline Cardiac arrest & $6(60 \%)$ & $4(40 \%)$ & $<.0001$ & $18.90(4.57-78.16)$ \\
\hline Atrial fibrillation (new onset) & $7(19.4 \%)$ & $29(80.6 \%)$ & ns & \\
\hline Paraplegia after ET & 0 & $1(100 \%)$ & $\mathrm{ns}$ & \\
\hline Major stroke & $3(50 \%)$ & $3(50 \%)$ & .018 & $14.65(2.24-95.84)$ \\
\hline Minor stroke & 0 & $2(100 \%)$ & $\mathrm{ns}$ & \\
\hline Postoperative renal failure & $9(45.0 \%)$ & $11(55.0 \%)$ & $<.0001$ & $13.91(4.34-44.59)$ \\
\hline Severe pulmonary dysfunction & $4(7.4 \%)$ & $50(92.6 \%)$ & ns & \\
\hline
\end{tabular}


TABLE 5. Continued

\begin{tabular}{|c|c|c|c|c|}
\hline \multirow[b]{2}{*}{ Risk factor } & \multicolumn{2}{|c|}{ Operative death (30 d) } & \multicolumn{2}{|c|}{ Univariate analysis } \\
\hline & Yes* $^{*}(\mathbf{n}=16)$ & No* $(n=130)$ & $\boldsymbol{P}$ & Odds ratio $(95 \% \mathrm{CI})$ \\
\hline Postoperative peripheral embolism & $3(50 \%)$ & $3(50 \%)$ & .018 & $14.65(2.24-95.84)$ \\
\hline Tracheostomy & $2(12.5 \%)$ & $14(87.5 \%)$ & ns & \\
\hline Sepsis & $2(40 \%)$ & $3(60 \%)$ & $\mathrm{ns}$ & \\
\hline Severe pulmonary infection & $4(21.1 \%)$ & $15(78.9 \%)$ & $\mathrm{ns}$ & \\
\hline Positive blood cultures & $1(25.0 \%)$ & $3(75.0 \%)$ & ns & \\
\hline Intestinal ischemia & $2(66.7 \%)$ & $1(33.3 \%)$ & .033 & $18.43(1.57-216.35)$ \\
\hline CPB time, $\min$ & $175(148-211)$ & $173(144-209)$ & $\mathrm{ns}$ & \\
\hline HCA time, min & $37(32-52)$ & $40(33-51)$ & ns & \\
\hline Crossclamp time, min & $105(84-137)$ & $100(75-121)$ & $\mathrm{ns}$ & \\
\hline Minimum hemoglobin, g/dL & $7.4(6.8-7.9)$ & $7.7(6.9-8.5)$ & $\mathrm{ns}$ & \\
\hline Bladder temperature (minimum), ${ }^{\circ} \mathrm{C}$ & $25.9(25.2-27.7)$ & $26(25-27.3)$ & ns & \\
\hline Blood loss postoperative, $\mathrm{mL}$ & $200(100-400)$ & $300(150-480)$ & $\mathrm{ns}$ & \\
\hline Mechanical ventilation, $\mathrm{h}$ & $109(65-149)$ & $38(19-108)$ & ns & \\
\hline Intensive care, $\mathrm{d}$ & $4.8(2.8-8.8)$ & $5.0(3.6-8.3)$ & $\mathrm{ns}$ & \\
\hline Plasma lactate, $\mathrm{mmol} / \mathrm{L}$ & $5.4(4.1-6.8 .8)$ & $5.2(4.2-6.6)$ & $\mathrm{ns}$ & \\
\hline
\end{tabular}

No patients needed surgical explant; one chimney graft was used to treat late dilatation of visceral vessels button in a patient undergoing OSR. Minor interventions included 1 case of visceral (left renal) branch thrombosis and 1 case of iliac limb graft occlusion, both managed with endovascular techniques and no clinical sequelae; visceral branch endoleaks occurred for distal disconnection in 2 cases and they were relined. There were 13 type II endoleaks, which required collateral embolization and/or iliac extensions.

CT follow-up showed sac shrinkage in only 12 patients (exclusively with dissection); significant sac enlargement was seen in 22 patients, all of whom had undergone further treatment with stent-grafts or endoleak treatment. In the remaining cases the lesions were stable. Cox regression models based on perioperative factors failed to indicate predictors of late death and of reoperation.

\section{DISCUSSION}

Diffuse aneurysmal disease is the consequence of various conditions that include chronic aortic dissection, inheritable pathologies of the connective tissue such as Marfan syndrome, and mega-aorta syndrome due to medial degenerative diseases. ${ }^{2}$ The ET technique, first described by Borst and colleagues ${ }^{23}$ in 1983, represents one of the most significant breakthroughs of modern aortic surgery. The rapid development of endovascular techniques subsequently resulted in unprecedented advances in vascular surgery. ${ }^{24,25}$ The principle of the Siena graft was to combine both surgical and endovascular advances to reduce procedural risks of all steps of repair and to expand the possibilities to treat challenging lesions involving the arch and the descending aorta. Hybrid grafts (such as Thoraflex Hybrid; Terumo Aortic) are standard only in limited aortic disease. In Siena, between December 2012 and January 2020, 76 patients received hybrid grafts: there were 33 dissections (28 chronic and 5 acute type A) and 43 were aneurysms (31 aortic arch penetrating ulcers); 66 patients were discharged alive from the hospital; only 27 patients, with limited aortic lesions, required no further endovascular extensions. We observed 3 cases with paraplegia after initial implant (none had a dissection), 3 cases of in graft-thrombosis (1 died), and 1 patient, with acute dissection, developed distal SINE tear, which determined visceral malperfusion and death. All these complications were quite unusual for traditional grafts and induced us to reconsider our initial optimism and reflect about the role of hybrid grafts: they are now reserved as primary indication, to lesions of limited extent, mainly PAUs or short aneurysm, that do not require further stent grafts; In addition, they are employed in particular anatomic configurations where a stented graft in the descending aorta may help further treatments. For dissection, either acute or chronic, hybrid grafts are not our first choice. Therefore, the unstented Siena graft remains essential for extensive lesions that require second-stage completion. ${ }^{26}$ In our experience, $47.4 \%$ of patients completed with TEVAR required more than 1 stent-graft and that the total length covered was longer than the maximal length covered by the stented portion of hybrid devices. Another advantage of the Siena graft is the creation of a reliable proximal neck 
TABLE 6. Outcomes after 114 endovascular procedures following the elephant trunk procedure

\begin{tabular}{|c|c|c|c|c|}
\hline & All & Dissection & Aneurysm & $P$ value \\
\hline All major endovascular procedures & 114 & 33 & 81 & .03 \\
\hline Planned second-stage completion & $97(85.0 \%)$ & $29(87.8 \%)$ & $68(83.9 \%)$ & $\mathrm{ns}$ \\
\hline Branched/chimney & 25 & 11 & 14 & .04 \\
\hline Standard stent-graft & 72 & 18 & 54 & \\
\hline Third-stage and extensions & $17(14.9 \%)$ & $4(12.1 \%)$ & $13(16.0 \%)$ & ns \\
\hline Branched stent-graft & 10 & 3 & 7 & ns \\
\hline Standard stent-graft & 7 & 1 & 6 & \\
\hline Treatment with standard stent-grafts (second and third stages only) & $79(69.2 \%)$ & $19(57.5 \%)$ & $60(74.0 \%)$ & .04 \\
\hline \multicolumn{5}{|l|}{ Stent-graft units per patient (straight) } \\
\hline 1 & 30 & 9 & 20 & ns \\
\hline 2 & 40 & 3 & 23 & .05 \\
\hline 3 & 13 & 2 & 11 & $\mathrm{~ns}$ \\
\hline Mean number of grafts per patients & 1.77 & 1.61 & 1.83 & .02 \\
\hline Straight stent-graft length, mm & 216 [155-338] & 155 [100-209] & 265 [199-345] & .006 \\
\hline Length covered from collar, mm & $182[154-214]$ & $168[155-197]$ & $184[154-214]$ & .001 \\
\hline Median stent-graft diameter, mm & $34[30-40]$ & $28[26-32]$ & $34[31-42]$ & $<.001$ \\
\hline Treatment with branched stent-graft (any stage) & $35(30.7 \%)$ & $14(42.2 \%)$ & $21(25.9 \%)$ & .01 \\
\hline Custom-made & 27 & 7 & 20 & .003 \\
\hline Off-the-shelf & 7 & 7 & 0 & $<.001$ \\
\hline Chimney & 1 & 0 & 1 & ns \\
\hline Antegrade/one-step procedure & 12 & 2 & 10 & ns \\
\hline Fenestration (second stage) & 18 & 18 & - & - \\
\hline Standard stent-graft + fenestration & 8 & 8 & - & - \\
\hline Branched stent-graft + fenestration & 10 & 10 & - & - \\
\hline Fenestration (third stage/extension) & 4 & 4 & & - \\
\hline With standard stent-graft & 1 & 1 & - & - \\
\hline With branched stent-graft & 3 & 3 & - & - \\
\hline \multicolumn{5}{|l|}{ Reinterventions } \\
\hline Thoracic/thoracoabdominal & 17 & 4 & 13 & ns \\
\hline Standard stent graft & 7 & 1 & 6 & - \\
\hline Branched stent graft & 10 & 3 & 7 & - \\
\hline Abdominal/iliac & 31 & 12 & 15 & .02 \\
\hline Renal/visceral & 5 & 3 & 1 & .06 \\
\hline Minor endoleak & 15 & 6 & 9 & $\mathrm{~ns}$ \\
\hline Other peripheral & 10 & 4 & 6 & ns \\
\hline Visceral branch complications & 5 & 2 & 3 & ns \\
\hline
\end{tabular}

Values are $\mathrm{n}(\%)$ or median [interquartile range]. $n s$, Not significant.

or landing zone for subsequent endovascular/surgical repair in lesions involving the distal arch with low procedural morbidity and a reduced rate of neurologic complications. ${ }^{27}$ This expanded ET concept means that lesions traditionally requiring thoracoabdominal incisions (and possibly circulatory arrest) are amenable to treatment through median sternotomy ( $29 \%$ of patients in this series). Our experience in dissection patients demonstrates that redirecting the arterial flow into the true lumen, resolving the arch reentries by arch replacement, and using the distal "soft" portion of the graft to cover lesions on the proximal part of the flap in the descending aorta, can result in the spontaneous thrombosis of the false lumen (19 patients with chronic dissection in this cohort). In connective tissue diseases, this classic ET (unstented or "soft") may represent an advantage, leaving open the possibility of a traditional completion of repair with the surgical polyester trunk. The Gelweave Siena collared graft represents a platform for further interventions without imposing a definitive choice for completion (endovascular or surgical). In dissected aortas, the difficulties advancing the graft inside compressed true lumens are easily overcome using a Goose neck device inserted from a femoral artery. Even with protective protocols, paraplegia or paraparesis are feared complications; despite early 


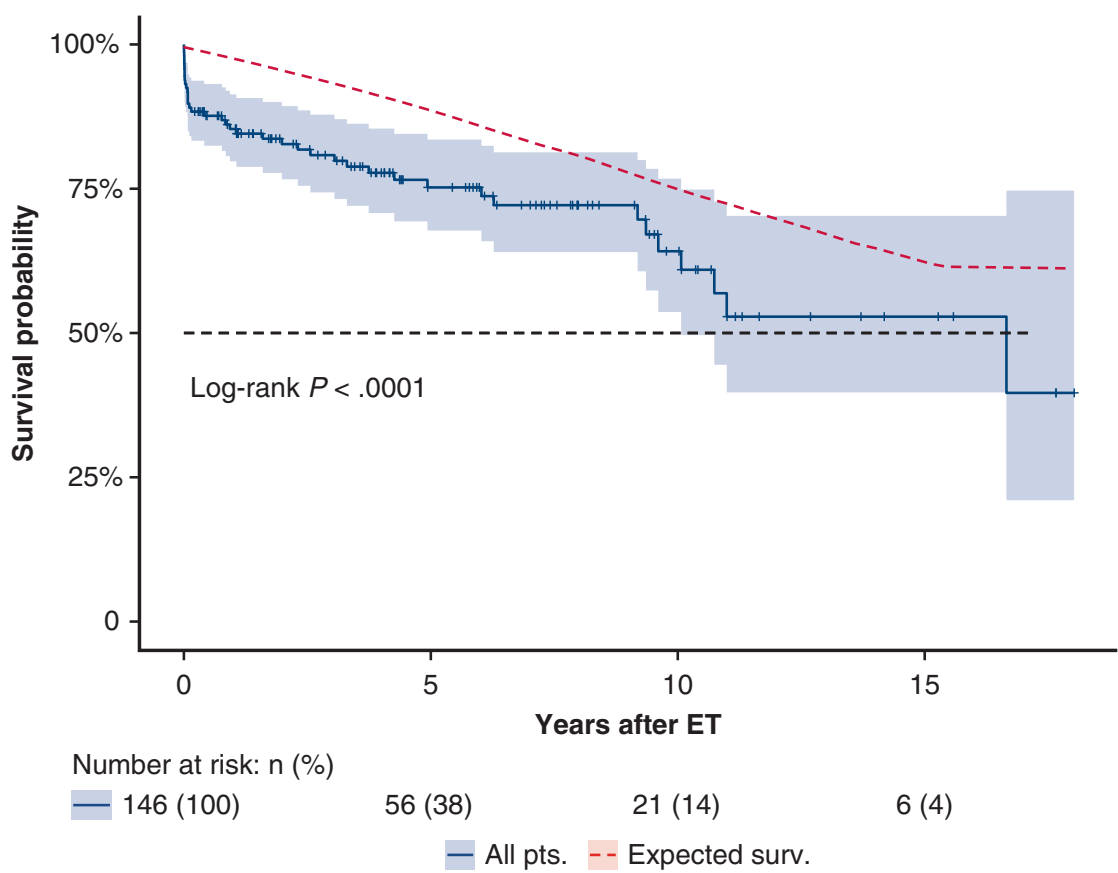

FIGURE 2. Kaplan-Meier estimates for overall survival after elephant trunk procedure of aneurysm and dissection groups. Survival of patients in the study was compared with the predicted survival experience (red line) for equivalent members of the general Italian population with respect to age and sex. The entire follow-up time (0-17.02 years) is presented; black dotted line represents median survival (16.65 years). The comparison with the predicted survival is statistically significant $(P<.0001)$; however, beyond the perioperative period (30 days), survival of the study population is comparable with that of the general population $(P=.44)$ with some differences (30 days to 5 years, $P=.59 ; 5-10$ years, $P=.06 ; 10-17$ years, $P=.35$ ). The analysis indicates that the approach is effective in achieving the goal of improving the outcome in this high-risk population. ET, Elephant trunk.

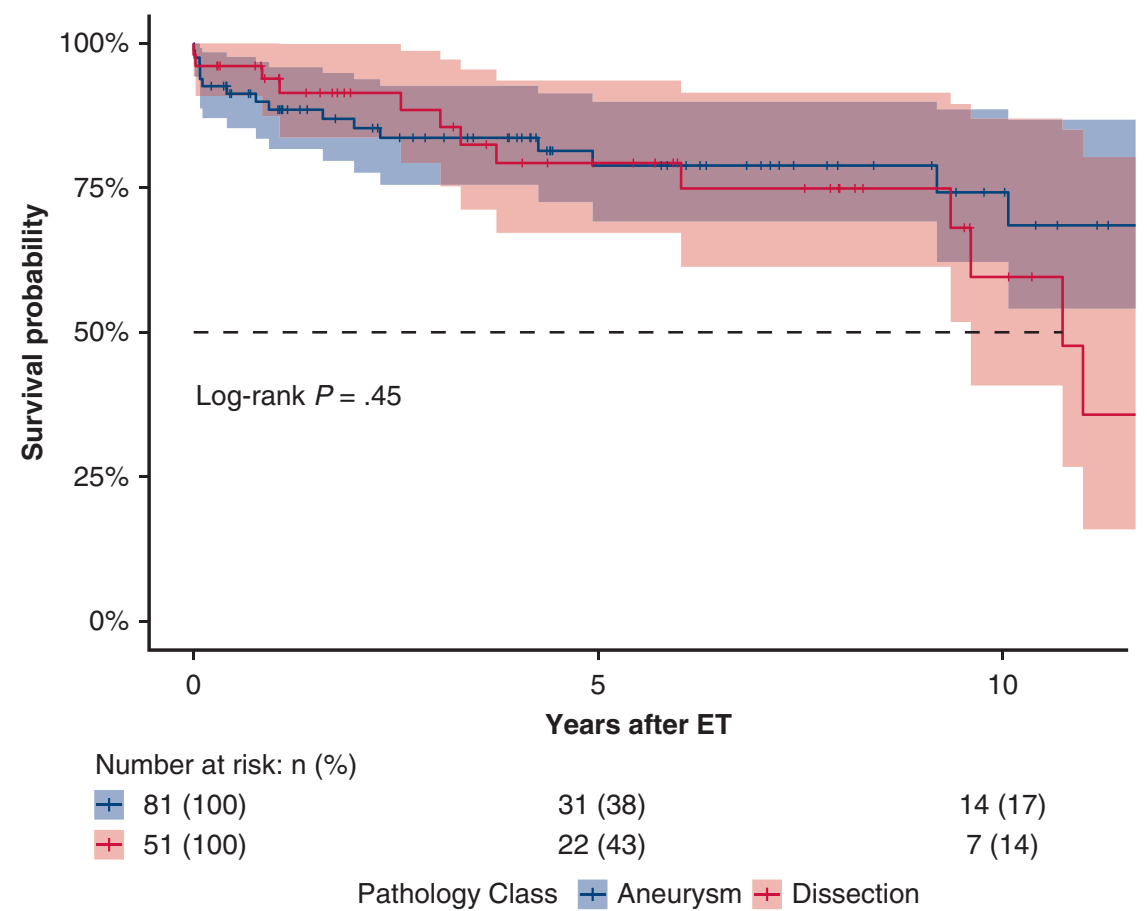

FIGURE 3. Results of elephant trunk procedures and subsequent treatments, according to our institutional approach to complex aortic pathology: Survival rates were analyzed for their relationship with underlying pathology (aneurysm and dissection); the log-rank test for differences in survival between the different groups was not significant $(P<.45)$. ET, Elephant trunk. 


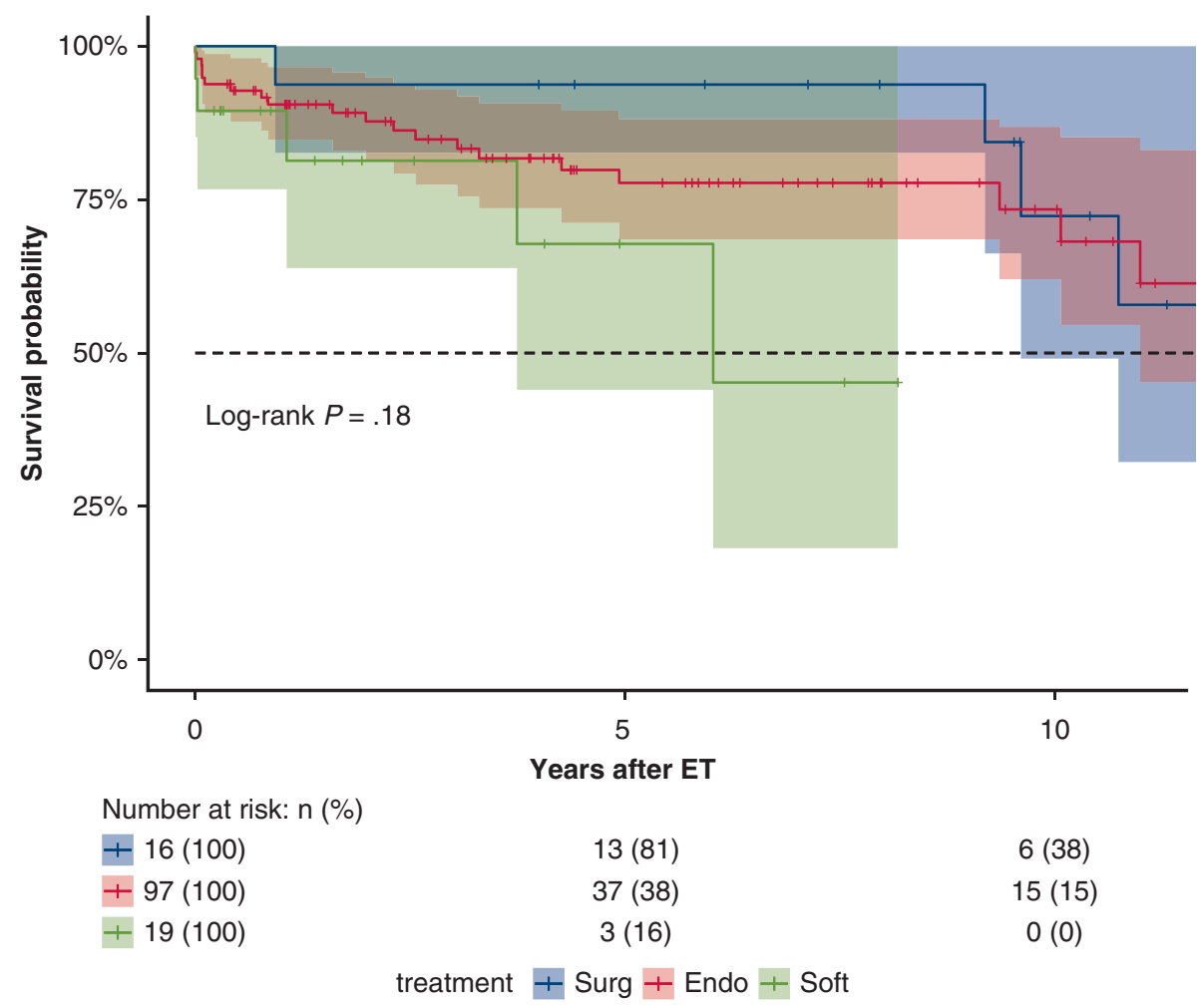

FIGURE 4. Kaplan-Meier estimates for overall survival after elephant trunk procedure comparing endovascular, surgical, and unstented ("soft") techniques; the "soft" approach was adopted mainly in dissection patients (16 dissection vs 3 aneurysm); this group does not include lost to follow up (1 patient), unfit ( 3 patients), pending treatment ( 1 patient), and died waiting completion ( $3 / 11$ patients: beyond 30 days from the index procedure). In this approach, the elephant trunk is left unstented into the true lumen. The result is considered acceptable if adequate remodeling of the false channel is obtained (eg, proximal thoracic aorta false channel thrombosis in absence of false channel compression or need of stricter follow up a severely dilated residual perfused false lumen distal to the end of the graft). All patients in the soft group died of nonaortic causes. All patients with planned "soft" approach who, in the course of followup, presented an unfavorable evolution, all underwent subsequent second-stage completion. ET, Elephant trunk.

optimism that endovascular techniques might reduce risk, extensive aortic coverage was associated with an incidence of spinal cord ischemia comparable with complex thoracic or thoracoabdominal surgical repair. ${ }^{28}$ Our series confirms these findings. Endovascular completion using straight stent-grafts above the celiac trunk was associated with a very low incidence of paraplegia (2 patients), whereas with branched stent-grafts, spinal cord ischemia (mostly delayed paraplegia) occurred in 8 patients despite routine CFS drainage. Stent-grafts result in sudden, complete occlusion of a large number of segmental vessels, and this occurs at relatively normothermic temperatures. ${ }^{18}$ Therefore, we favored from the beginning, staged procedures, with the treatment of the most critical segments of the aorta. Furthermore, persistent perfusion of the false lumen the presence of endoleaks appears to be protective against paraplegia in patients with complete aortic endovascular coverage so, unless necessary for aortic dimensions or impending rupture, we have adopted the policy of leaving a deliberate, temporary "endoleak" via an unconnected branch, and delay branching the visceral arteries. Recently, we have used custom-made designs to include a fifth branch for sac perfusion (the so-called "paraplegia prevention branch"), which is closed percutaneously with a plug at least 1 month after the main procedure. ${ }^{29}$ The choice of the TEVAR prosthesis did not affect survival, nor the incidence for repeat procedure. Our rule is that it is the patient's anatomy that guides the selection of devices; at the beginning of this experience, devices were few and certain features were not available; recently, the market has become more mature with increased choice for individual planning, especially for branched and custom-made prostheses. Off-shelf prostheses have the advantage of being quickly available and have so far been represented by only one model.

Our series contains a small number of patients who underwent arch replacement for acute dissection using the Siena graft. Beyond the debate about more extensive arch approach, the principal reason is that in dissections requiring arch replacement we prefer to use 2 different grafts, one for the ET and one for the arch, given that the collar offers no technical advantage in small and fragile aortas; more recently, we have adopted other techniques such as intimal relayering for arch repair dissection. ${ }^{30}$ 


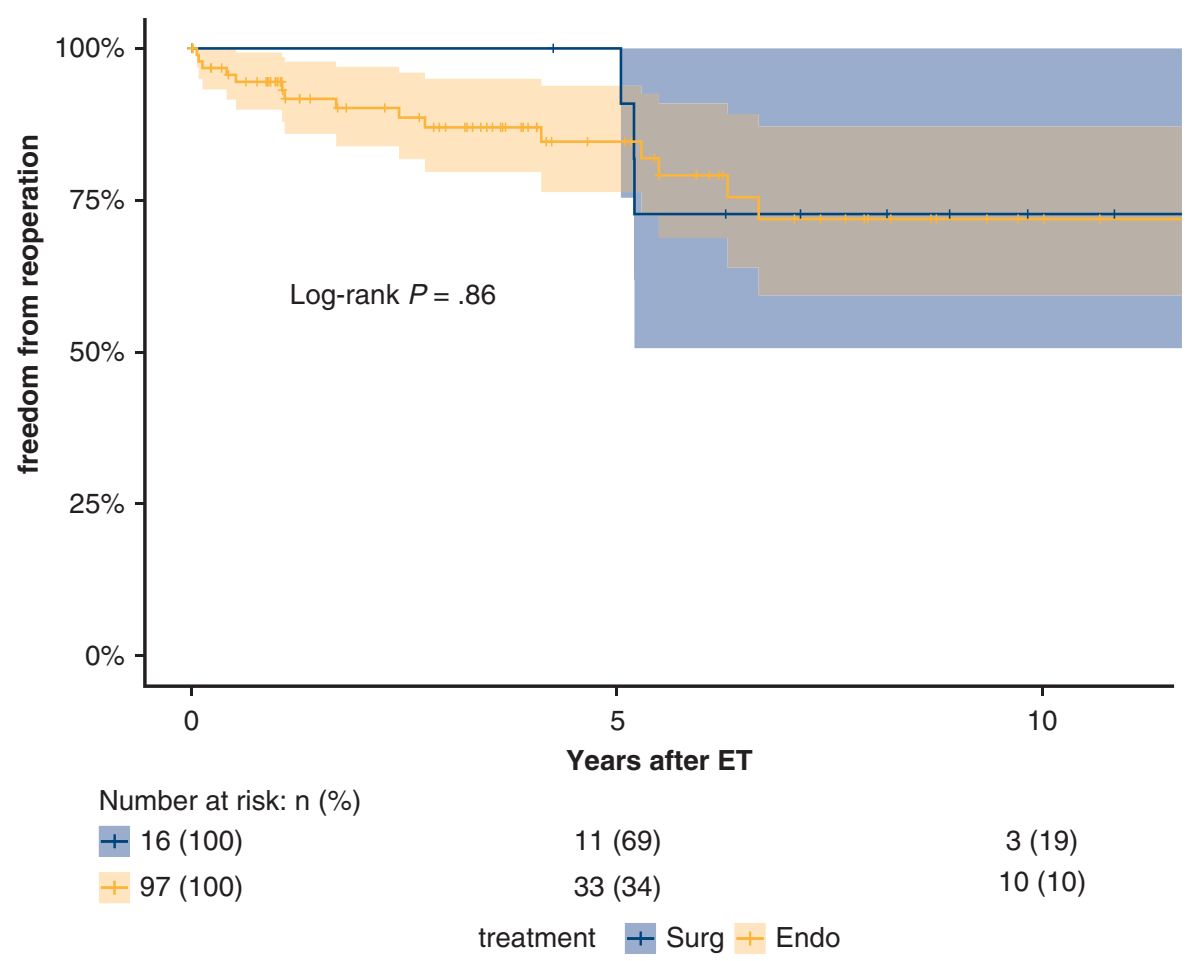

FIGURE 5. The Kaplan-Meier estimates for freedom from reintervention after elephant trunk procedure according to treatment type (endovascular or surgical): the plot illustrates a different behavior, between the surgical and endovascular populations, with regard to the need of subsequent reinterventions. The surgical repair seems more stable over the time and reinterventions refer mainly to dilatation of visceral button reimplantation. Endovascular treatments require further corrections scattered along the entire study period, thus demonstrating the need of a close and lifelong follow-up. ET, Elephant trunk.

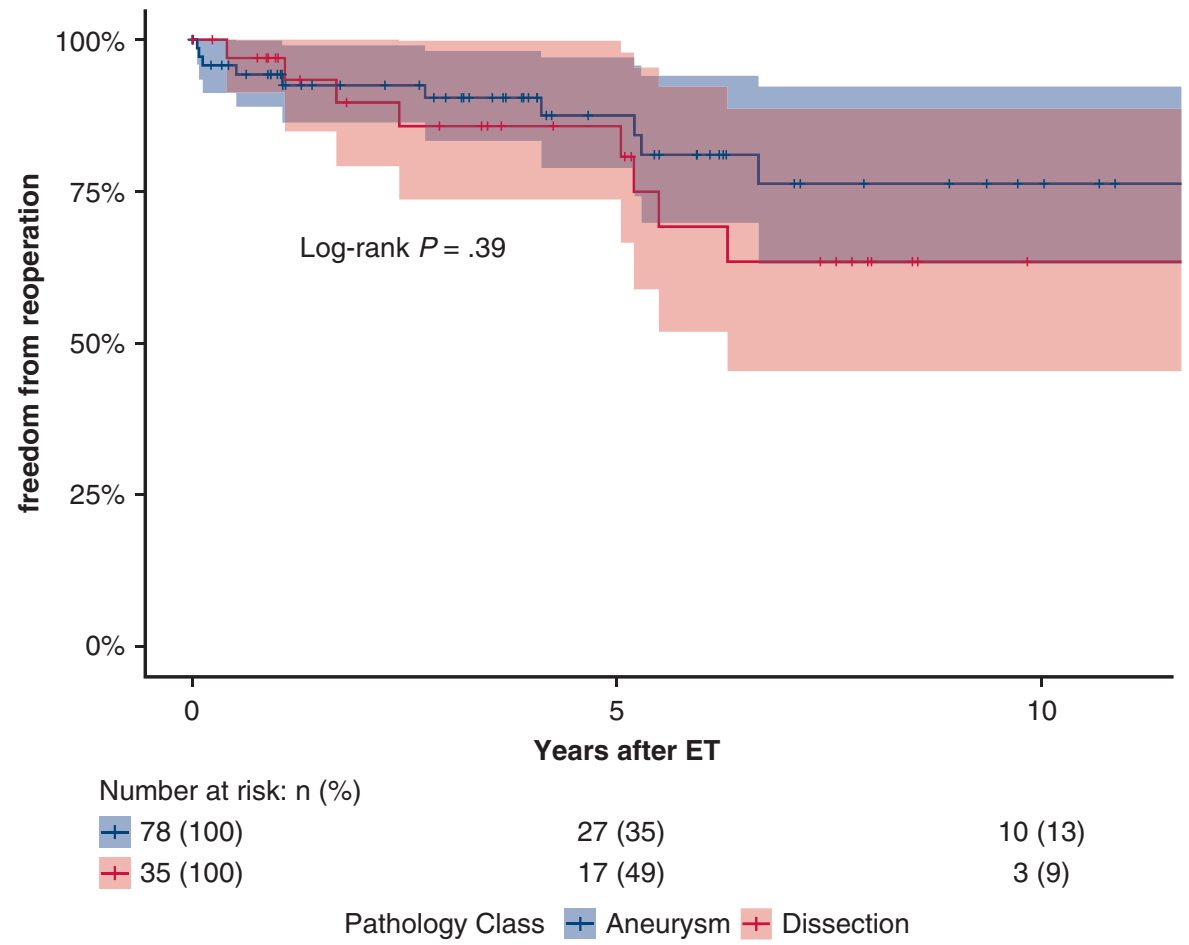

FIGURE 6. Kaplan-Meier estimates for freedom from reintervention after elephant trunk procedure according to pathology: both aneurysm or dissection patients require further treatments after elephant trunk completion; we do not appreciate a significant behavior with regard to the underlying pathology: this is probably attributable to the intensive use of endovascular grafts, more than to the pathology itself. Differences between groups are not significant with the log-rang test. ET, Elephant trunk. 
Marfan syndrome and other connective tissue disorders are commonly considered contraindications for endovascular surgery; in our series, there were 14 patients with Marfan syndrome ( 8 chronic dissections and 6 aneurysms) who had undergone arch replacement: of these, only 6 underwent surgical completion; the remaining were treated with endovascular devices. Six dissection patients underwent extensive fenestration of the flap, with implantation of branched grafts and bifurcated aortoiliac extensions. Proximal landing zone for endovascular devices was the Dacron ET. Two subjects with aneurysms were treated respectively with a straight graft above the diaphragm and a custommade branched graft; in both cases, treatment was a personal choice of the patient. Clinical follow-up was uncomplicated, and no reoperation was recorded. Our limited experience does not authorize any conclusion on the use of these devices, and the results, although satisfactory, do not allow us to suggest its use in this patient population; our perception is that, in subjects with connective tissue disease, extensive fenestrations and a prosthetic proximal landing zone may overcome the most common complications of aortic stent graft placement, such as SINE or endovascular-induced neck dilatation.

The presented series includes 17 patients (Table 4) who had undergone delayed sternal closure and mediastinal packing. The indication was mainly a persistent nonsurgical bleeding for coagulation disorders; only 3 had right ventricular failure with difficulties of sternal reapproximation. Packing is obtained with a technique ${ }^{31}$ developed by us, which involves the use of polyurethane open cell foam, vacuum, and adhesive membranes; applied for a short period (618 hours), this method appears to effectively reduce blood loss, transfusion requirements, sternal re-exploration, and mediastinal infections.

\section{CONCLUSIONS}

Aortic arch replacement, using appropriate devices with current methods of cerebral protection and less-invasive perfusion techniques, has reached a phase of technical maturity, robust reproducibility, safety, and widespread adoption. The Siena graft is a reliable method for complex aortic pathologies and has some advantages over the hybrid devices. The Siena graft remains an important treatment option catering to different pathologies and surgical techniques providing comprehensive solutions for the surgeon and patient. The breakthrough of endovascular devices and ancillary techniques observed in recent years expands the role of ET procedures in the settings of complex aortic treatment strategies.

Beyond any technical consideration, in this patient population, a rigorous follow-up is necessary and represents an essential tool to ensure these patients the right times and the best interventions for the management of their conditions.

\section{Conflict of Interest Statement}

E.N. consults for and, until September 2015, received royalties from, Terumo Aortic. All other authors reported no conflicts of interest.

The Journal policy requires editors and reviewers to disclose conflicts of interest and to decline handling or reviewing manuscripts for which they may have a conflict of interest. The editors and reviewers of this article have no conflicts of interest.

\section{References}

1. Neri E, Massetti M, Sani G. The "elephant trunk" technique made easier. Ann Thorac Surg. 2004;78:e17-8.

2. Crawford ES, Coselli JS, Svensson LG, Safi HJ, Hess KR. Diffuse aneurysmal disease (chronic aortic dissection, Marfan, and mega aorta syndromes) and multiple aneurysm. Treatment by subtotal and total aortic replacement emphasizing the elephant trunk operation. Ann Surg. 1990;211:521-37.

3. Schneider SRB, Dell'Aquila AM, Akil A, Schlarb D, Panuccio G, Martens S, et al. Results of "elephant trunk" total aortic arch replacement using a multibranched, collared graft prosthesis. Heart Vessels. 2016;31:390-6.

4. Ouzounian M, LeMaire SA, Coselli JS. Open aortic arch repair: state-of-the-art and future perspectives. Semin Thorac Cardiovasc Surg. 2013;25:107-15.

5. LeMaire SA, Price MD, Parenti JL, Johnson ML, Lay AD, Preventza O, et al. Early outcomes after aortic arch replacement by using the Y-graft technique. Ann Thorac Surg. 2011;91:700-8.

6. Castrovinci S, Murana G, de Maat GE, Smith T, Schepens MAAM, Heijmen RH, et al. The classic elephant trunk technique for staged thoracic and thoracoabdominal aortic repair: long-term results. J Thorac Cardiovasc Surg. 2015;149: 416-22.

7. Di Eusanio M. Frozen elephant trunk surgery: evolving grafts and techniques. Eur J Cardiothorac Surg. 2013;43:411-2.

8. Elefteriades JA. Natural history of thoracic aortic aneurysms: indications for surgery, and surgical versus nonsurgical risks. Ann Thorac Surg. 2002;74:S1877-80.

9. Hiratzka LF, Bakris GL, Beckman JA, Bersin RM, Carr VF, Casey DE Jr, et al. 2010 ACCF/AHA/AATS/ACR/ASA/SCA/SCAI/SIR/STS/SVM guidelines for the diagnosis and management of patients with thoracic aortic disease. Circulation. 2010;121:e266-9.

10. Harky A, Kai Chan JS, Ming Wong CH, Bashir M. Open versus endovascular repair of descending thoracic aortic aneurysm disease: a systematic review and meta-analysis. Ann Vasc Surg. 2019;54:304-15.e5.

11. Neri E, Massetti M, Barabesi L, Pula G, Tassi R, Toscano T, et al. Extrathoracic cannulation of the left common carotid artery in thoracic aorta operations through a left thoracotomy: preliminary experience in 26 patients. $J$ Thorac Cardiovasc Surg. 2002;123:901-10.

12. Kazui T, Washiyama N, Muhammad BAH, Terada H, Yamashita K, Takinami M, et al. Total arch replacement using aortic arch branched grafts with the aid of antegrade selective cerebral perfusion. Ann Thorac Surg. 2000;70:3-8.

13. Tsukube T, Yoshimura M, Matsuda H, Okada K, Matsukawa R, Hino Y, et al. Ribcross thoracotomy for replacement of the thoracoabdominal or total descending aorta. J Vasc Surg. 2003;37:219-21.

14. Lucatelli P, Cini M, Benvenuti A, Saba L, Tommasino G, Guaccio G, et al. Custom-made endograft for endovascular repair of thoraco-abdominal aneurysm and type B dissection: single-centre experience. Cardiovasc Intervent Radiol. 2018;41:1174-83.

15. Winnerkvist A, Lockowandt U, Rasmussen E, Rådegran K. A prospective study of medically treated acute type B aortic dissection. Eur J Vasc Endovasc Surg. 2006;32:349-55.

16. Barshes NR, Gravereaux EC, Semel M, Bolman RM, Belkin M. Endovascular longitudinal fenestration and stent graft placement for treatment of aneurysms developing after chronic type B aortic dissection. J Vasc Surg. 2015;61:1366-9.

17. Ricci C, Ceccherini C, Leonini S, Cini M, Vigni F, Neri E, et al. JAG tearing technique with radiofrequency guide wire for aortic fenestration in thoracic endovascular aneurysm repair. Cardiovasc Intervent Radiol. 2012;35:176-9.

18. Griepp RB, Griepp EB. Spinal cord perfusion and protection during descending thoracic and thoracoabdominal aortic surgery: the collateral network concept. Ann Thorac Surg. 2007;83:S865-9.

19. Etz CD, Weigang E, Hartert M, Lonn L, Mestres CA, Di Bartolomeo R, et al. Contemporary spinal cord protection during thoracic and thoracoabdominal 
aortic surgery and endovascular aortic repair: a position paper of the vascular domain of the European Association for Cardio-Thoracic Surgery. Eur J Cardiothorac Surg. 2015;47:943-57.

20. Wong CS, Healy D, Canning C, Coffey JC, Boyle JR, Walsh SR. A systematic review of spinal cord injury and cerebrospinal fluid drainage after thoracic aortic endografting. J Vasc Surg. 2012;56:1438-47.

21. Scott DA, Denton MJ. Spinal cord protection in aortic endovascular surgery. $\mathrm{Br}$ J Anaesth. 2016;117(suppl_2):ii26-31.

22. Chiesa R, Melissano G, Marrocco-Trischitta MM, Civilini E, Setacci F. Spinal cord ischemia after elective stent-graft repair of the thoracic aorta. J Vasc Surg. 2005;42:11-7.

23. Borst HG, Walterbusch G, Schaps D. Extensive aortic replacement using "elephant trunk" prosthesis. Thorac Cardiovasc Surg. 1983;31:37-40.

24. Parodi JC, Palmaz JC, Barone HD. Transfemoral intraluminal graft implantation for abdominal aortic aneurysms. Ann Vasc Surg. 1991;5:491-9.

25. Dake MD, Miller DC, Semba CP, Mitchell RS, Walker PJ, Liddell RP. Transluminal placement of endovascular stent-grafts for the treatment of descending thoracic aortic aneurysms. N Engl J Med. 1994;331:1729-34.

26. Ma W-G, Zheng J, Sun L-Z, Elefteriades JA. Open stented grafts for frozen elephant trunk technique: technical aspects and current outcomes. Aorta (Stamford). 2015;3:122-35.
27. Preventza O, Tan CW, Orozco-Sevilla V, Euhus CJ, Coselli JS. Zone zero hybric arch exclusion versus open total arch replacement. Ann Cardiothorac Surg. 2018; 7:372-9.

28. Bobadilla JL, Wynn M, Tefera G, Acher CW. Low incidence of paraplegia after thoracic endovascular aneurysm repair with proactive spinal cord protective protocols. J Vasc Surg. 2013;57:1537-42.

29. Lioupis C, Corriveau MM, MacKenzie KS, Obrand DI, Steinmetz OK, Ivancev K, et al. Paraplegia prevention branches: a new adjunct for preventing or treating spinal cord injury after endovascular repair of thoracoabdominal aneurysms. J Vasc Surg. 2011;54:252-7.

30. Neri E, Tucci E, Tommasino G, Guaccio G, Ricci C, Lucatelli P, et al. Intimal re-layering technique for type A acute aortic dissection-reconstructing the intimal layer continuity to induce remodeling of the false channel. $J$ Vis Surg. 2018;4:82.

31. Muzzi L, Tommasino G, Tucci E, Neri E. Successful use of a military haemostatic agent in patients undergoing extracorporeal circulatory assistance and delayed sternal closure. Interact Cardiovasc Thorac Surg. 2012;14:695-8.

Key Words: aorta, aortic arch surgery, elephant trunk technique, thoracic endovascular repair 